\title{
A Modified o-Phthalaldehyde Fluorometric Analytical Method for Ultratrace Ammonium in Natural Waters Using EDTA-NaOH as Buffer
}

\author{
Hongzhi Hu, ${ }^{1,2}$ Ying Liang, ${ }^{1}$ Shuo Li, ${ }^{1}$ Qing Guo, ${ }^{1}$ and Chancui Wu ${ }^{1}$ \\ ${ }^{1}$ School of Life and Environmental Sciences, Guilin University of Electronic Technology, Guilin 541004, China \\ ${ }^{2}$ School of Automation Engineering, University of Electronic Science and Technology of China, Chengdu 611731, China \\ Correspondence should be addressed to Ying Liang; yingl@aliyun.com and Qing Guo; sxgq@guet.edu.cn
}

Received 25 August 2014; Revised 16 October 2014; Accepted 16 October 2014; Published 11 November 2014

Academic Editor: Jesus Simal-Gandara

Copyright (C) 2014 Hongzhi Hu et al. This is an open access article distributed under the Creative Commons Attribution License, which permits unrestricted use, distribution, and reproduction in any medium, provided the original work is properly cited.

\begin{abstract}
In the existence of appropriate amount of disodium ethylenediaminetetraacetate (EDTA), precipitation would not occur in seawater and other natural waters even if the sample solution was adjusted to strong basicity, and the $\mathrm{NH}_{3}$-OPA-sulfite reaction at the optimal $\mathrm{pH}$ range could be used to determine ammonium in natural waters. Based on this, a modified $o$-phthalaldehyde fluorometric analytical method has been established to determine ultratrace ammonium in natural waters. Experimental parameters, including reagent concentration, $\mathrm{pH}$, reaction time, and effect of EDTA, were optimized throughout the experiments based on univariate experimental design. The results showed that the optimal $\mathrm{pH}$ range was between 10.80 and 11.70. EDTA did not obviously affect the fluorometric intensity. The linearity range of the proposed method was $0.032-0.500 \mu \mathrm{mol} / \mathrm{L}, 0.250-3.00 \mu \mathrm{mol} / \mathrm{L}$, and $1.00-$ $20.0 \mu \mathrm{mol} / \mathrm{L}$ at the excitation/emission slit of $3 \mathrm{~nm} / 5 \mathrm{~nm}, 3 \mathrm{~nm} / 3 \mathrm{~nm}$, and $1.5 \mathrm{~nm} / 1.5 \mathrm{~nm}$, respectively. The method detection limit was $0.0099 \mu \mathrm{mol} / \mathrm{L}$. Compared to the classical OPA method, the proposed method had the advantage of being more sensitive and could quantify ultratrace ammonium without enrichment.
\end{abstract}

\section{Introduction}

Ammonia nitrogen consists of ammonia $\left(\mathrm{NH}_{3}\right)$ and ammonium $\left(\mathrm{NH}_{4}^{+}\right)$in natural waters. Ammonium is predominant when the $\mathrm{pH}$ is below 8.75, and ammonia is predominant when $\mathrm{pH}$ is above 9.75 [1]. Ammonium is the main species in the $\mathrm{pH}$ range of most natural waters and is an essential nutrient in aquatic ecosystems [2]. The concentration of ammonium is usually more than micromolar level in mostly continental water and coastal seawater, even up to millimolar level due to environmental pollution [3]. However, it is less than micromolar level, even down to nanomolar level in ocean water [4]. The accurate measurement of ammonium concentrations is fundamental to understanding nitrogen biogeochemistry in aquatic ecosystems. The most common techniques used to measure ammonium in freshwater and seawater are the indophenol blue method $[5,6]$ and $o$ phthalaldehyde (OPA) fluorometric method [7-15]. The $o$ phthalaldehyde (OPA) fluorometric method is much more sensitive than the indophenol blue method. It has attracted a great deal of attention of scientists. In 1971, it was firstly reported that OPA could react with amino acid and ammonium in the existence of mercaptoethanol to produce a strongly fluorescent compound [7]. In 1989, the reaction was modified by replacing mercaptoethanol with sulfite, organic amine compounds did not interfere in the determination, and an OPA fluorometric method with higher sensitivity and selectivity was developed for ammonium by Genfa and Dasgupta [8]. Afterwards, the method was further modified for the determination of ammonium in seawater [9-11] and was developed for shipboard using flow injection technology [12-14]. Recently, the sensitivity of the OPA method was further remarkably improved to determine ocean surface water by combining fluorescence detection with flow analysis and solid phase extraction [15]. The main analytical parameters of the OPA methods mentioned above were listed in Table 1. The lower limit of quantitation (LOQ) listed in the table was the lowest concentration of the working range 
TABLE 1: The main analytical parameters of the typical reported OPA methods.

\begin{tabular}{|c|c|c|c|c|c|c|}
\hline Samples & Technology & Reagent & $\begin{array}{l}\text { Reaction } \\
\text { temperature }\end{array}$ & $\begin{array}{c}\text { Working range } \\
(\mathrm{nmol} / \mathrm{L})\end{array}$ & $\begin{array}{c}\text { LOQ } \\
(\mathrm{nmol} / \mathrm{L})\end{array}$ & Reference \\
\hline Standard solution & Manual & OPA, mercaptoethanol & Room temperature & $1.0 \times 10^{5}-1.0 \times 10^{6}$ & $1.0 \times 10^{5}$ & [7] \\
\hline Fresh water & Flow injection & $\begin{array}{c}\mathrm{OPA}, \mathrm{Na}_{2} \mathrm{SO}_{3} \\
\text { phosphate }\end{array}$ & $85^{\circ} \mathrm{C}$ & $250-20000$ & 250 & {$[8]$} \\
\hline Fresh/saline waters & Flow injection & OPA, $\mathrm{Na}_{2} \mathrm{SO}_{3}$, tetraborate & $30^{\circ} \mathrm{C}$ & $250-50000$ & 250 & {$[9]$} \\
\hline Seawater & Manual & OPA, $\mathrm{Na}_{2} \mathrm{SO}_{3}$, tetraborate & Room temperature & ND-10000 & ND & {$[10]$} \\
\hline Seawater & Gas diffusion & $\mathrm{OPA}, \mathrm{Na}_{2} \mathrm{SO}_{3}$ & $70^{\circ} \mathrm{C}$ & ND-40000 & ND & {$[11]$} \\
\hline Seawater & Flow injection & OPA, $\mathrm{Na}_{2} \mathrm{SO}_{3}$ & $65^{\circ} \mathrm{C}$ & $100-600$ & 100 & {$[12]$} \\
\hline Seawater & $\begin{array}{c}\text { Autonomous batch } \\
\text { analyzer }\end{array}$ & OPA, $\mathrm{Na}_{2} \mathrm{SO}_{3}$ & Room temperature & $200-1000$ & 200 & {$[13]$} \\
\hline Seawater & $\begin{array}{c}\text { Multipumping } \\
\text { analyzer }\end{array}$ & OPA, $\mathrm{Na}_{2} \mathrm{SO}_{3}$, tetraborate & $63.5-86.5^{\circ} \mathrm{C}$ & $13-1000$ & 13 & {$[14]$} \\
\hline Seawater & $\begin{array}{l}\text { Solid extraction } \\
\text { technology }\end{array}$ & OPA, $\mathrm{Na}_{2} \mathrm{SO}_{3}$, tetraborate & $75^{\circ} \mathrm{C}$ & $1.67-300$ & 1.67 & {$[15]$} \\
\hline
\end{tabular}

* LOQ: the lower limit of quantitation, the lowest concentration of the standard curves or working range reported in the corresponding reference. ND means "no data."

in the corresponding references. Table 1 showed that the sensitivity of the reported methods was gradually improved and the LOQ was decreased using advanced technology such as flow injection, autonomous batch, and solid extraction technology.

The fluorometric reaction of $\mathrm{NH}_{3}$-OPA-sulfite was found to be $\mathrm{pH}$ dependent by much reported work. The optimal $\mathrm{pH}$ was reported at 11 by Amornthammarong and Zhang in 2008 [12]. However, when $\mathrm{pH}$ was more than 10.4, precipitation easily occurred due to the existence of metal ions in natural water sample. To avoid precipitation of the metal ions, much work had to control the $\mathrm{pH}$ about 9.3 using sodium tetraborate solution as buffer $[9,10,14,15]$. According to the reported data, the sensitivity of the method at $\mathrm{pH}=9.3$ was several times less than that at $\mathrm{pH}=11$. Therefore, it was considered that the method sensitivity could be also proved by changing the reaction $\mathrm{pH}$. In this work, a modified $\mathrm{NH}_{3}$-OPA-sulfite reaction using EDTA-NaOH as buffer was described. In the existence of appropriate amount of EDTA, precipitation would not occur in natural water even if the solution was adjusted to strong basicity, and the $\mathrm{NH}_{3}$-OPA-sulfite reaction under the optimal $\mathrm{pH}$ condition could be used to determine ammonium in natural waters. Based on this, a new modified $o$-phthalaldehyde fluorometric analytical method was established. The method is highly sensitive for determination of ammonium in natural waters without enrichment.

\section{Experimental}

2.1. Reagents and Solutions. All the chemicals used in this study were of analytical grade, supplied by Aladdin Chemical Reagent Co., China, unless stated otherwise. All solutions were prepared in ultrapure water (resistivity $18.2 \mathrm{M} \Omega \cdot \mathrm{cm}$ ).

Standard Solution. Ammonium standard stock solution (1000 mg N/L) was purchased from Aladdin Chemical
Reagent Co. Ammonium standard substock solution (10 $\mathrm{mmol} \mathrm{NH}_{4}{ }^{+} / \mathrm{L}$ ) was prepared monthly by diluting the stock solution with ultrapure water. The stock and substock solutions were stored at $4^{\circ} \mathrm{C}$ in a refrigerator while not in use. Ammonium working solution $\left(0.1 \mathrm{mmol} \mathrm{NH}_{4}{ }^{+} / \mathrm{L}\right)$ was prepared daily by diluting $1.0 \mathrm{~mL}$ of the substock solution to $100 \mathrm{~mL}$ with ultrapure water.

Fluorescent Reagent Solution $\left(R_{1}\right) .10 .6 \mathrm{~g} / \mathrm{L}$ OPA solution (Reagent A) was made by dissolving $2.65 \mathrm{~g}$ of OPA in $50 \mathrm{~mL}$ of methanol (HPLC grade) and diluted to $250 \mathrm{~mL}$ with ultrapure water. $2.5 \mathrm{~g} / \mathrm{L}$ sodium sulfite solution (Reagent B) was made by dissolving $1.25 \mathrm{~g}$ of $\mathrm{Na}_{2} \mathrm{SO}_{3}$ in $500 \mathrm{~mL}$ ultrapure water and adding $0.20 \mathrm{~mL} \mathrm{HCHO}$ to prevent the solution from being oxidized. To reduce reagent blank, fluorescent reagent solution $\left(R_{1}\right)$ was prepared daily by mixing equal volumes of Reagent A with Reagent B and allowed to stand in room temperature for at least 2 hours and then passed through the OASIS HLB $6 \mathrm{cc} / 200 \mathrm{mg}$ cartridge (Waters Corp., Millford, $\mathrm{MA})$ at a flow rate of $3.0 \mathrm{~mL} / \mathrm{min}$ before use.

EDTA-NaOH Buffer Solution $\left(R_{2}\right)$ and $\mathrm{NaOH}$ Solution. EDTA-NaOH buffer solution $\left(\mathrm{R}_{2}\right)$ was made by dissolving $46.6 \mathrm{~g}$ disodium ethylenediaminetetraacetate (EDTA, ACS grade) and $8.75 \mathrm{~g} \mathrm{NaOH}$ (ACS grade) in $500 \mathrm{~mL}$ ultrapure water. $\mathrm{NaOH}$ solution $\left(\mathrm{R}_{3}\right)$ was made by dissolving $10.0 \mathrm{~g}$ $\mathrm{NaOH}$ (ACS grade) in $500 \mathrm{~mL}$ ultrapure water. Sodium tetraborate buffer solution $\left(\mathrm{R}_{4}\right)$ was prepared by dissolving $3.75 \mathrm{~g} \mathrm{Na}_{2} \mathrm{~B}_{4} \mathrm{O}_{7} \cdot 10 \mathrm{H}_{2} \mathrm{O}$ in $500 \mathrm{~mL}$ ultrapure water. These above-mentioned three solutions were separately boiled for several ten minutes to remove ammonia till the final volume of the solution was reduced to half of the original volume and were immediately cooled in water bath and tightly sealed in a polypropylene bottle. The bottles were double-bagged using polyethylene bag while not in use.

All vessels used in the experiments were firstly soaked with $1 \mathrm{~mol} \cdot \mathrm{L}^{-1} \mathrm{HCl}$ for more than 12 hours and cleaned with $\mathrm{RO}$ water and then were soaked with $1 \mathrm{~mol} \cdot \mathrm{L}^{-1} \mathrm{NaOH}$ at least 
for 12 hours and cleaned thoroughly with ultrapure water before use.

\subsection{Analytical Procedures}

2.2.1. The Proposed Method. $20 \mathrm{~mL}$ of standard ammonium solution or sample solution with a concentration range of $0.032-15.0 \mu \mathrm{mol} / \mathrm{L}$ was exactly measured into a polypropylene bottle. Appropriate amounts of fluorescent reagent $\left(\mathrm{R}_{1}\right)$ and buffer $\left(\mathrm{R}_{2}\right)$ were added into the solution. The concentrations of OPA, sodium sulfite, and EDTA in the final solution were $0.691 \mathrm{~g} / \mathrm{L}, 0.163 \mathrm{~g} / \mathrm{L}$, and $5.77 \mathrm{mmol} / \mathrm{L}$, respectively. The $\mathrm{pH}$ of the final solution was controlled in the range of 11.011.4 by adding appropriate amounts of $\mathrm{NaOH}$ solution $\left(\mathrm{R}_{3}\right)$. After all the reagents were added, the mixed solution was tightly sealed and allowed to react for 50 minutes at room temperature. At least ten samples could be determined at the same time. The fluorescence intensity (FI) was measured on a fluorescence spectrophotometer (RF-5301PC, SHIMADZU Co., Ltd., Japan) with excitation wavelength set at $361 \mathrm{~nm}$ and emission wavelength at $423 \mathrm{~nm}$.

2.2.2. The Classical OPA Method. Based on the method of $[10,15], 20 \mathrm{~mL}$ of standard ammonium solution or sample solution with a concentration range of $0.250-2.00 \mu \mathrm{mol} / \mathrm{L}$ was exactly measured into a polypropylene bottle. Both $3 \mathrm{~mL}$ of fluorescent reagent $\left(\mathrm{R}_{1}\right)$ and $5 \mathrm{~mL}$ of sodium tetraborate buffer $\left(R_{4}\right)$ were added to the solution. After all the reagents were added, the mixed solution was tightly sealed and allowed to react for 60 minutes at room temperature. The $\mathrm{pH}$ of the reaction solution is about 9.3. The fluorescence intensity (FI) was measured in the same instrument as the proposed method.

\section{Results and Discussion}

3.1. Parameters Optimization. The OPA- $\mathrm{NH}_{3}$-sulfite reaction may be affected by the parameters OPA and sodium sulfite concentrations, reaction time, and $\mathrm{pH}$. These parameters had been optimized by much work [7-10]. However, the reaction system in this work was different from previous works due to adding EDTA-NaOH buffer solution, so they were optimized based on a univariate experimental design again.

3.1.1. Spectral Characteristics of the Reaction Production. $0.25 \mu \mathrm{mol} / \mathrm{L}$ standard ammonium solution was allowed to react with OPA and sodium sulfite in the presence of EDTA$\mathrm{NaOH}$ buffer according to Section 2.2.1. The excitation and emission spectra of the reaction product are showed in Figure 1.

The product had the maximum excitation wavelength $\left(\lambda_{\text {ex }}\right)$ at $361 \mathrm{~nm}$ and the maximum emission wavelength $\left(\lambda_{\mathrm{em}}\right)$ at $423 \mathrm{~nm}$, showing similar spectral characteristics as reported by Genfa and Dasgupta (1989). The results indicated that the spectral characteristics were not affected by EDTA. The time necessary for completion of the OPA-sulfite- $\mathrm{NH}_{3}$

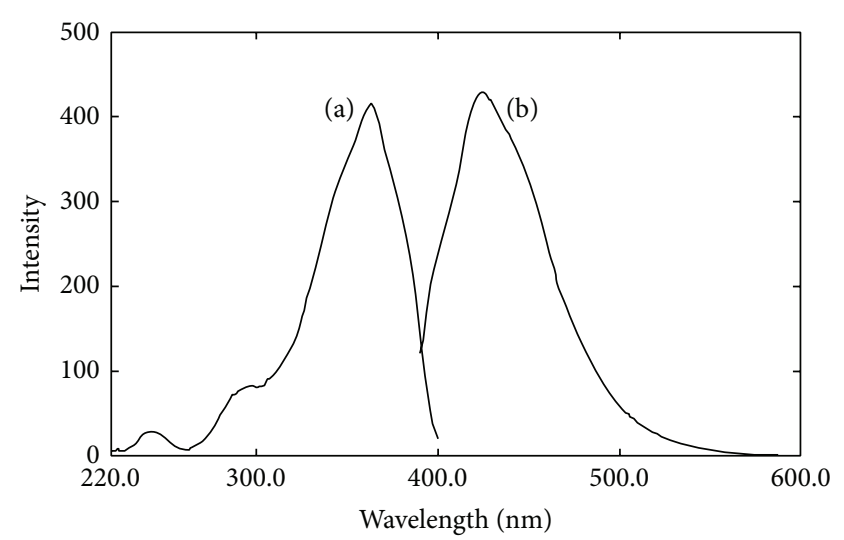

FIgURE 1: Excitation (a) and emission (b) spectra of products of OPA- $\mathrm{NH}_{3}$-sulfite ( $\mathrm{pH}$ 11.3) in the presence of EDTA.

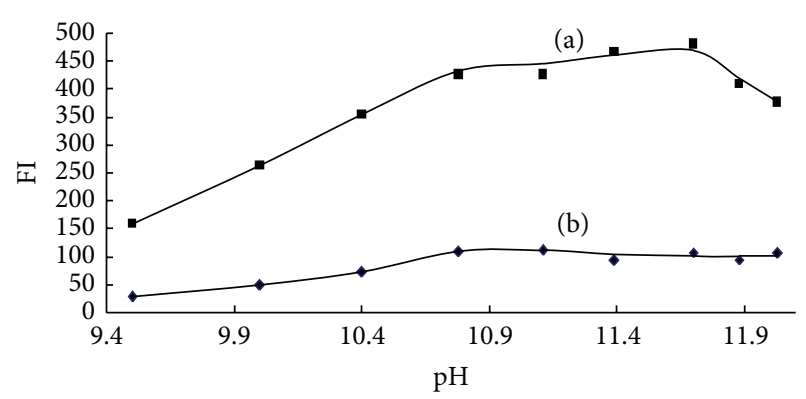

FIGURE 2: Effect of $\mathrm{pH}$ on the reaction of OPA- $\mathrm{NH}_{3}$-sulfite ((a) $0.25 \mu \mathrm{mol} / \mathrm{L}$, (b) blank).

reaction under this condition was about $50 \mathrm{~min}$ at room temperature. The excitation wavelength, emission wavelength, and reaction time were chosen as $361 \mathrm{~nm}, 423 \mathrm{~nm}$, and $50 \mathrm{~min}$ in the following investigations, respectively.

3.1.2. Effect of $\mathrm{pH}$ on the Reaction of $\mathrm{OPA}-\mathrm{NH}_{3}$-Sulfite. It was reported that the OPA-NH -sulfite reaction could be $\mathrm{pH}$ dependent and formed a fluorescent isoindole complex [16]. The optimal $\mathrm{pH}$ was at the range of 10-10.5 reported by Kuo et al. [17] and at 11 reported by Amornthammarong and Zhang [12]. The optimal range of $\mathrm{pH}$ reported in different paper was not completely uniform, but it was agreed that the $\mathrm{pH}$ had obvious influence on the formation of fluorescent isoindole complex. In this work, the effect of $\mathrm{pH}$ that varied from 9.5 to 12.0 was investigated. As showed in Figure 2, the fluorescence intensity (FI) increased with increasing $\mathrm{pH}$ from 9.5 up to 10.80 , the maximum FI was observed in the $\mathrm{pH}$ range of 10.80-11.70, and then the FI decreased when the $\mathrm{pH}$ was higher than 11.70. The maximum FI was about three times of that of $\mathrm{pH}=9.5$. The variation trend and optimal $\mathrm{pH}$ range are similar to those of Amornthammarong and Zhang [12]. To gain better method sensitivity, the solution $\mathrm{pH}$ was controlled in the range of 11.0-11.4 using EDTA-NaOH buffer solution in this work. The EDTA effect was discussed in detail in Section 3.1.4. 
TABLE 2: The FI of different concentration standard ammonium solution in existence and absence of EDTA.

\begin{tabular}{lcc}
\hline Concentration of ammonium $\left(C_{N}, \mu \mathrm{mol} / \mathrm{L}\right)$ & FI in existence of EDTA & FI in absence of EDTA \\
\hline 0 & 62.871 & 74.994 \\
0.125 & 253.749 & 235.408 \\
0.250 & 444.613 & 414.782 \\
0.375 & 589.166 & 551.247 \\
0.500 & 760.241 & 690.585 \\
\hline The relationship between FI and $C_{N}$ & $\mathrm{FI}=1384.1 C_{N}+76.10(n=5)$ & $\mathrm{FI}=1237.6 C_{N}+84.00(n=5)$ \\
\hline Corresponding parameters & $0.9973(P<0.0001)$ & $0.9970(P<0.0001)$ \\
$\quad R^{2}$ & 12.65 & 11.90 \\
$\quad$ The standard deviation of the intercept & 41.32 & 38.87 \\
$\quad$ The standard deviation of the slope & & \\
\end{tabular}

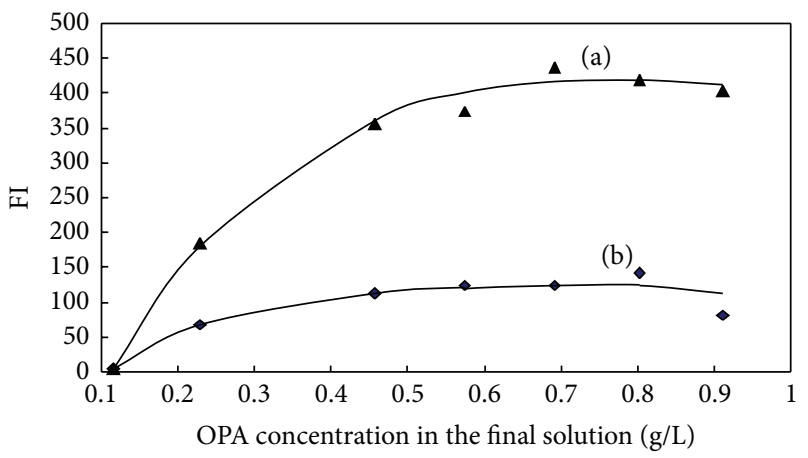

FIGURE 3: Effect of OPA concentration in the final solution on the reaction of OPA- $\mathrm{NH}_{3}$-sulfite ((a) $0.25 \mu \mathrm{mol} / \mathrm{L}$, (b) blank).

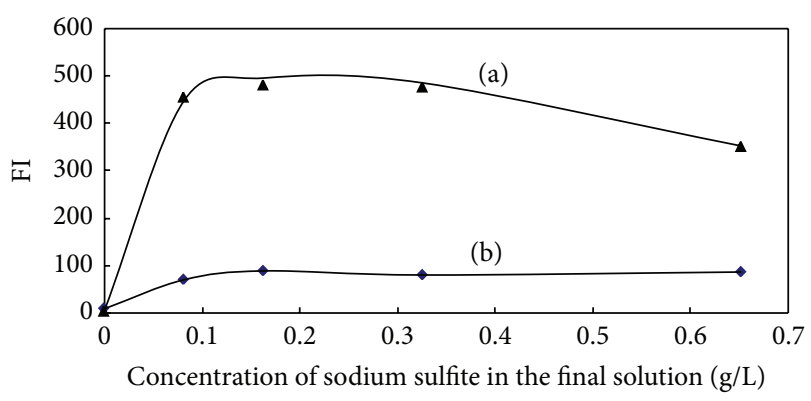

FIGURE 4: Effect of sodium sulfite concentration in the final solution on the reaction of OPA- $\mathrm{NH}_{3}$-sulfite ((a) $0.25 \mu \mathrm{mol} / \mathrm{L}$, (b) blank).

\subsubsection{Effect of Concentrations of OPA and Sodium Sulfite.} The effect of OPA concentration on the fluorescence reaction was studied over the range $0.115-0.913 \mathrm{~g} / \mathrm{L}$ (Figure 3 ). The fluorescence intensity increased with increasing OPA concentration from 0.115 up to $0.457 \mathrm{~g} / \mathrm{L}$ and was kept stable when the OPA concentration was between 0.457 and $0.913 \mathrm{~g} / \mathrm{L}$. Consequently, an OPA concentration of $0.691 \mathrm{~g} / \mathrm{L}$ in the final solution was chosen for all subsequent experiments.

The effect of sodium sulfite in the range of $0-10 \mathrm{~g} / \mathrm{L}$ is illuminated in Figure 4. The fluorescence intensity increased rapidly when concentration of sodium sulfite increased from 0 to $0.081 \mathrm{~g} / \mathrm{L}$ and was kept constant in the range of $0.081-$ $0.326 \mathrm{~g} / \mathrm{L}$, and then the intensity slowly decreased when the sodium sulfite concentration was more than $0.326 \mathrm{~g} / \mathrm{L}$. Therefore, a sodium sulfite concentration of $0.163 \mathrm{~g} / \mathrm{L}$ in the final solution was selected in this work.

In this work, OPA and sodium sulfite were found to be the main source of reagent blank. To decrease the reagent blank, OPA and sodium sulfite solution were mixed together according to the depiction in Section 2.1 and passed through a HLB cartridge. In the mixed solution, ammonium in the reagent reacted with excess OPA and sodium sulfite and produced isoindole complex. The isoindole complex could be extracted by HLB column, ammonium in the solution was removed. Most of OPA and sodium sulfite in the solution passed through the column. The passed solution was used as fluorescent reagent. It was stable for one week if stored at $4^{\circ} \mathrm{C}$ in a refrigerator, while the reagent blank will slowly increase because of the effect of ambient air. To get lower reagent blank, the mixed solution was made daily in this work.

3.1.4. Effect of EDTA. EDTA is a strong metal ion complexing agent. Precipitation would not occur in seawater sample at the existence of appropriate number of EDTA even if the solution was adjusted to strong basicity. When $3 \mathrm{~mL}$ of EDTA-NaOH buffer solution $\left(\mathrm{R}_{2}\right)$ was added in $20 \mathrm{~mL}$ seawater sample in this work, the $\mathrm{pH}$ of the solution could be adjusted in the range of 11.0-11.4 and precipitation could not appear. The concentration of EDTA in the final solution was $5.77 \mathrm{mmol} / \mathrm{L}$. This dosage was also suitable for determining freshwater sample. To investigate the effect of EDTA, the FI of different concentration standard ammonium solution was separately determined in the existence or absence of EDTA. The results are listed in Table 2. There was not an obvious difference between the FI signals of existence and absence of EDTA, illuminating that EDTA had not obviously influence the fluorimetric determination of ammonium. EDTA could be used to prevent metal ion precipitation in this proposed method.

3.2. Calibration Curves, Sensitivity, Reproducibility, and Method Detection Limit. Under the optimal conditions chosen above, the typical calibration curves were determined according to Section 2.2.1. The results are listed in Table 3. The linearity range was $0.032-0.500,0.250-3.00$, and $1.00-$ $20.0 \mu \mathrm{mol} / \mathrm{L}$ at the excitation/emission slit of $3 \mathrm{~nm} / 5 \mathrm{~nm}$, 
TABLE 3: Calibration curves and the corresponding performances.

\begin{tabular}{|c|c|c|c|c|c|c|c|}
\hline Method & $\begin{array}{l}\text { Excitation/emission } \\
\text { slit widths }\end{array}$ & Calibration curves & $n$ & $R^{2}$ & $\begin{array}{c}\text { Standard } \\
\text { deviation of the } \\
\text { intercept }\end{array}$ & $\begin{array}{c}\text { Standard } \\
\text { deviation of the } \\
\text { slope }\end{array}$ & $\begin{array}{l}\text { Linearity } \\
\text { range } \\
(\mu \mathrm{mol} / \mathrm{L})\end{array}$ \\
\hline \multirow{3}{*}{ The proposed method } & $3 \mathrm{~nm} / 5 \mathrm{~nm}$ & $\mathrm{FI}=1237.6 C_{N}+84.0$ & 6 & 0.9970 & 11.90 & 38.87 & $0.032-0.500$ \\
\hline & $3 \mathrm{~nm} / 3 \mathrm{~nm}$ & $\mathrm{FI}=283.0 C_{N}+35.8$ & 6 & 0.9996 & 4.88 & 2.94 & $0.25-3.00$ \\
\hline & $1.5 \mathrm{~nm} / 1.5 \mathrm{~nm}$ & $\mathrm{FI}=36.6 C_{N}+20.7$ & 8 & 0.9971 & 5.58 & 0.81 & $1.00-15.0$ \\
\hline The classical method & $3 \mathrm{~nm} / 5 \mathrm{~nm}$ & $\mathrm{FI}=312.6 C_{N}+60.7$ & 6 & 0.9951 & 5.71 & 12.66 & $0.25-2.00$ \\
\hline
\end{tabular}

TABLE 4: The matrix spiked recovery.

\begin{tabular}{lccc}
\hline Matrix & Matrix spiked curve & Corresponding calibration curve & The average matrix spiked recovery \\
\hline Groundwater & $\mathrm{FI}=1240 C_{N}+162.0$ & $\mathrm{FI}=1220 C_{N}+125.2$ & $101.60 \%$ \\
$\left(n=5, R^{2}=0.9961\right)$ & $\left(n=5, R^{2}=0.9955\right)$ & $103.83 \%$ \\
\hline Mountain spring water & $\begin{array}{c}\mathrm{FI}=1194 C_{N}+246.2 \\
\left(n=5, R^{2}=0.9908\right)\end{array}$ & $\begin{array}{c}\mathrm{FI}=1150 C_{N}+172.0 \\
\left(n=5, R^{2}=0.9941\right)\end{array}$ & $97.60 \%$ \\
\hline Seawater & $\mathrm{FI}=915.1 C_{N}+118.2$ & $\mathrm{FI}=937.8 C_{N}+119.4$ \\
$\left(n=5, R^{2}=0.9912\right)$ & $\left(n=5, R^{2}=0.9923\right)$ & 9 \\
\hline
\end{tabular}

TABLE 5: Analytical results of the proposed method and classical OPA method.

\begin{tabular}{lcccc}
\hline $\begin{array}{l}\text { Seawater } \\
\text { sample }\end{array}$ & $\begin{array}{c}\text { The proposed method } \\
(\mu \mathrm{mol} / \mathrm{L})\end{array}$ & $\begin{array}{c}\text { The classical OPA method } \\
(\mu \mathrm{mol} / \mathrm{L})\end{array}$ & Calculated $t$-value & Critical $t$-value $(P=0.05)$ \\
\hline 1 & $0.536 \pm 0.008(n=4)$ & $0.560 \pm 0.018(n=4)$ & 2.43 & 2.45 \\
2 & $0.385 \pm 0.006(n=3)$ & $0.360 \pm 0.035(n=3)$ & 1.22 & 2.78 \\
\hline
\end{tabular}

$3 \mathrm{~nm} / 3 \mathrm{~nm}$, and $1.5 \mathrm{~nm} / 1.5 \mathrm{~nm}$, respectively. The calibration curve with different linearity range could be used for typical sample analysis, depending on the concentration of ammonium in water samples.

Under the same experimental environment as the proposed method, a calibration curve of the classical OPA method was determined according to Section 2.2.2 and was $\mathrm{FI}=312.6 C_{N}+60.7$ at the excitation/emission slit of $3 \mathrm{~nm} / 5 \mathrm{~nm}$ (Table 3 ). The slope of the proposed method is 1237.6, being 4 times that of the classical OPA method. This illuminated that the proposed method was much more sensitive than the classical method.

The reproducibility of the method was evaluated with 5 repetitive determinations of a $0.250 \mu \mathrm{mol} / \mathrm{L}$ ammonium standard solution. The relative standard deviation was $3.2 \%$. Eleven blanks solutions were determined at the excitation/emission slit of $3 \mathrm{~nm} / 5 \mathrm{~nm}$, the average FI was 45.71 , and the standard deviation was 4.09 . The method detection limit, estimated as three times the standard deviations of the blank, was $0.0099 \mu \mathrm{mol} / \mathrm{L}$.

\subsection{Validation of the Method}

3.3.1. Recovery. Fresh water samples, groundwater and mountain spring water, were collected at Yaoshan Scenic Area in Guilin. A surface seawater sample was collected from the South China Sea and aged for one year. In order to examine the recovery of the method, these three samples spiked with a series of concentration of ammonium $(0,0.125$,
$0.250,0.500$, and $1.000 \mu \mathrm{mol} / \mathrm{L})$ were separately analyzed using the proposed method, together with the calibration curve. The linear equations of the matrix spike curves and corresponding calibration curves are showed in Table 4 . The slopes of the calibration curves were not completely identical due to the slight difference of the room temperature and other environmental parameters in different days. To avoid the influence of the experimental environment, the matrix spiked curve and the corresponding calibration curve were determined in the same time. The recovery of the ammonium in spiked samples was represented as the ratio of the slope of matrix spike curve to that of corresponding calibration curve [18]. The average recovery of the ammonium in fresh water and seawater matrix ranged from $97.60 \%$ to $103.83 \%$, illuminating that the other amine in the water samples did not disturb the determination of ammonium. The proposed method is available for both fresh water and seawater.

3.3.2. Comparison with Classical OPA Method. Two typical seawater samples obtained from the South China Sea were analyzed using the proposed method according to Section 2.2.1. At the same time, the ammonium concentrations were determined using classical OPA method according to Section 2.2.2. The results are compared in Table 5. Using the paired Student's $t$-test at $95 \%$ confidence level to test the difference between the two methods, the calculated $t$ values were lower than the critical $t$-value. This indicates that there was no statistically significant difference between the proposed method and classical OPA method. 


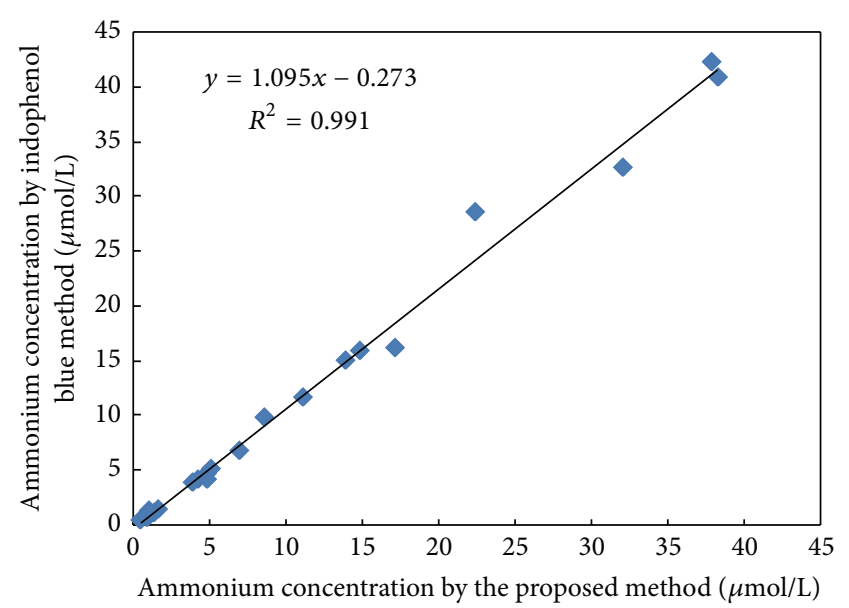

FIGURE 5: Intercomparison data with indophenol blue method.

3.3.3. Application. Huajian River is located in Guilin city and passes through Huajian Compus of Guilin University of Electronic Technology (GUET). Twenty-three surface water samples were collected from Huajian River at December 27, 2013, and filtered by $0.45 \mu \mathrm{m}$ filter as soon as possible after collection. The filtered water samples were refrigerated at $4^{\circ} \mathrm{C}$ before determination. The samples were analyzed by both the proposed method and indophenol blue method [5] within 24 hours. When the concentration of ammonium in the water sample was less than $15 \mu \mathrm{mol} / \mathrm{L}$, the FI of the water sample was determined according to Section 2.2.1, and the calibration curve with appropriate linearity range in Table 3 was applied to quantify the ammonium concentration. Otherwise, the water sample should be diluted before determination. The results in Figure 5 show a good agreement between these two methods with a wide concentration range from 0.44 to $38.25 \mu \mathrm{mol} / \mathrm{L}$. The spatial variation of ammonium in Huajian River is described in Figure 6. The higher concentrations of ammonium were found in the River at about $500 \mathrm{~m}$ downstream of GUET. The concentration of ammonium in the upstream was lower and decreased gradually as the distance to the GUET was increasing. This illuminated that the outfall of GUET was the most possible main source of ammonium in the river.

\section{Conclusion}

A new modified OPA fluorometric analytical method was established to determine ultratrace concentrations ammonium in natural waters using EDTA-NaOH as buffer. In this method, the $\mathrm{NH}_{3}$-OPA-sulfite reaction at the optimal $\mathrm{pH}$ could be used to determine ammonium in natural waters. There was no significant statistical difference between the results obtained from the proposed method and classical OPA method. The results of the proposed method applied to determine the river water were agreed with that of indophenol blue method. Compared to the classical OPA method, the main merit of the proposed method was enhancing the sensitivity by increasing the amount of reaction production

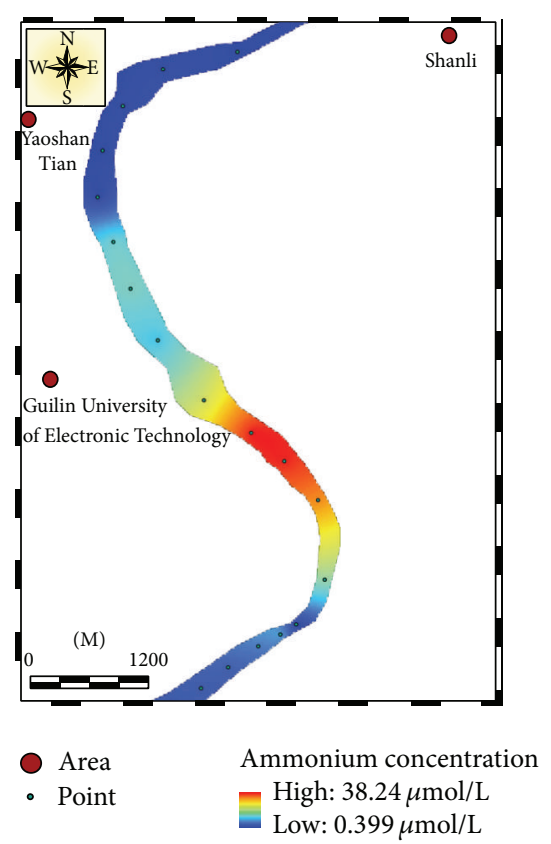

FIgURE 6: The spatial variation of ammonium concentration in Huajian River.

under the optimal $\mathrm{pH}$ condition. It could quantify nanomolar level ammonium without enrichment.

\section{Conflict of Interests}

The authors declare that there is no conflict of interests regarding the publication of this paper.

\section{Acknowledgments}

The work was financially supported by the National Natural Science Foundation of China (no. 41206077). The authors would like to thank the group of Professor Yuan Dongxing in Xiamen University for supplying the seawater samples.

\section{References}

[1] C. Molins-Legua, S. Meseguer-Lloret, Y. Moliner-Martinez, and P. Campíns-Falcó, "A guide for selecting the most appropriate method for ammonium determination in water analysis," TrAC Trends in Analytical Chemistry, vol. 25, no. 3, pp. 282-290, 2006.

[2] W. G. Harrison, L. R. Harris, and B. D. Irwin, "The kinetics of nitrogen utilization in the oceanic mixed layer: nitrate and ammonium interactions at nanomolar concentrations," Limnology and Oceanography, vol. 41, no. 1, pp. 16-32, 1996.

[3] S. J. Painting, M. J. Devlin, S. J. Malcolm et al., "Assessing the impact of nutrient enrichment in estuaries: susceptibility to eutrophication," Marine Pollution Bulletin, vol. 55, no. 1-6, pp. 74-90, 2007.

[4] M. T. Johnson, P. S. Liss, T. G. Bell et al., "Field observations of the ocean-atmosphere exchange of ammonia: fundamental importance of temperature as revealed by a comparison of high 
and low latitudes," Global Biogeochemical Cycles, vol. 22, no. 1, Article ID GB1019, pp. 1-15, 2008.

[5] I. Ivančič and D. Degobbis, "An optimal manual procedure for ammonia analysis in natural waters by the indophenol blue method," Water Research, vol. 18, no. 9, pp. 1143-1147, 1984.

[6] G. Chen, M. Zhang, Z. Zhang, Y. Huang, and D. Yuan, "Online solid phase extraction and spectrophotometric detection with flow technique for the determination of nanomolar level ammonium in seawater samples," Analytical Letters, vol. 44, no. 1-3, pp. 310-326, 2011.

[7] M. Roth, "Fluorescence reaction for amino acids," Analytical Chemistry, vol. 43, no. 7, pp. 880-882, 1971.

[8] Z. Genfa and P. K. Dasgupta, "Fluorometric measurement of aqueous ammonium ion in a flow injection system," Analytical Chemistry, vol. 61, no. 5, pp. 408-412, 1989.

[9] A. Aminot, R. Kérouel, and D. Birot, "A flow injectionfluorometric method for the determination of ammonium in fresh and saline waters with a view to in situ analyses," Water Research, vol. 35, no. 7, pp. 1777-1785, 2001.

[10] X. X. Yu and W. D. Guo, "Sensitive spectrofluorimetric method for determination of low concentration ammonium in seawater," Marine Sciences, vol. 31, no. 4, pp. 37-41, 2007 (Chinese).

[11] R. J. Watson, E. C. V. Butler, L. A. Clementson, and K. M. Berry, "Flow-injection analysis with fluorescence detection for the determination of trace levels of ammonium in seawater," Journal of Environmental Monitoring, vol. 7, no. 1, pp. 37-42, 2005.

[12] N. Amornthammarong and J.-Z. Zhang, "Shipboard fluorometric flow analyzer for high-resolution underway measurement of ammonium in seawater," Analytical Chemistry, vol. 80, no. 4, pp. 1019-1026, 2008.

[13] N. Amornthammarong, J.-Z. Zhang, and P. B. Ortner, "An autonomous batch analyzer for the determination of trace ammonium in natural waters using fluorometric detection," Analytical Methods, vol. 3, no. 7, pp. 1501-1506, 2011.

[14] B. Horstkotte, C. M. Duarte, and V. Cerdà, "A miniature and field-applicable multipumping flow analyzer for ammonium monitoring in seawater with fluorescence detection," Talanta, vol. 85, no. 1, pp. 380-385, 2011.

[15] Y. Zhu, D. X. Yuan, Y. M. Huang, J. Ma, and S. C. Feng, "A sensitive flow-batch system for on board determination of ultra-trace ammonium in seawater: method development and shipboard application," Analytica Chimica Acta, vol. 794, pp. 4754, 2013.

[16] E. Trepman and R. F. Chen, "Fluorescence stopped-flow study of the o-phthaldialdehyde reaction," Archives of Biochemistry and Biophysics, vol. 204, no. 2, pp. 524-532, 1980.

[17] C. T. Kuo, P. Y. Wang, and C. H. Wu, "Fluorometric determination of ammonium ion by ion chromatography using postcolumn derivatization with o-phthaldialdehyde," Journal of Chromatography A, vol. 1085, no. 1, pp. 91-97, 2005.

[18] Y. Liang, D. Yuan, Q. Li, and Q. Lin, "Flow injection analysis of nanomolar level orthophosphate in seawater with solid phase enrichment and colorimetric detection," Marine Chemistry, vol. 103, no. 1-2, pp. 122-130, 2007. 

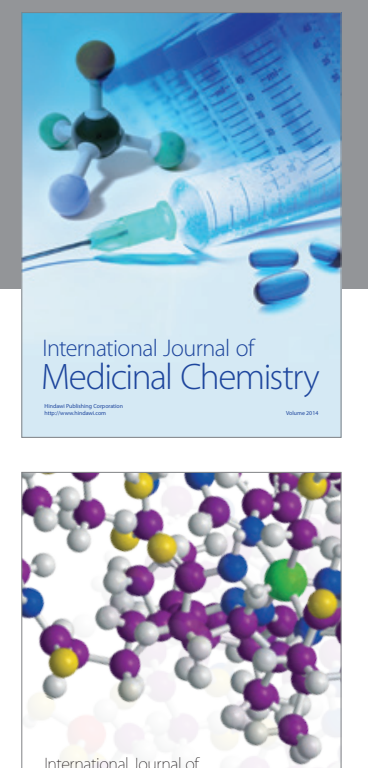

\section{Carbohydrate} Chemistry

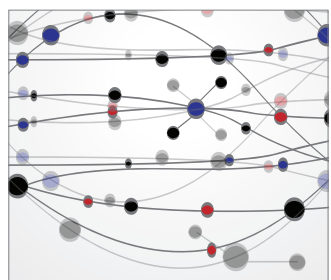

The Scientific World Journal
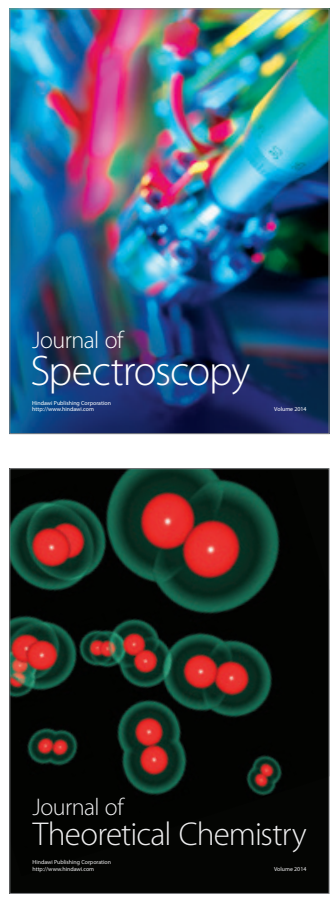
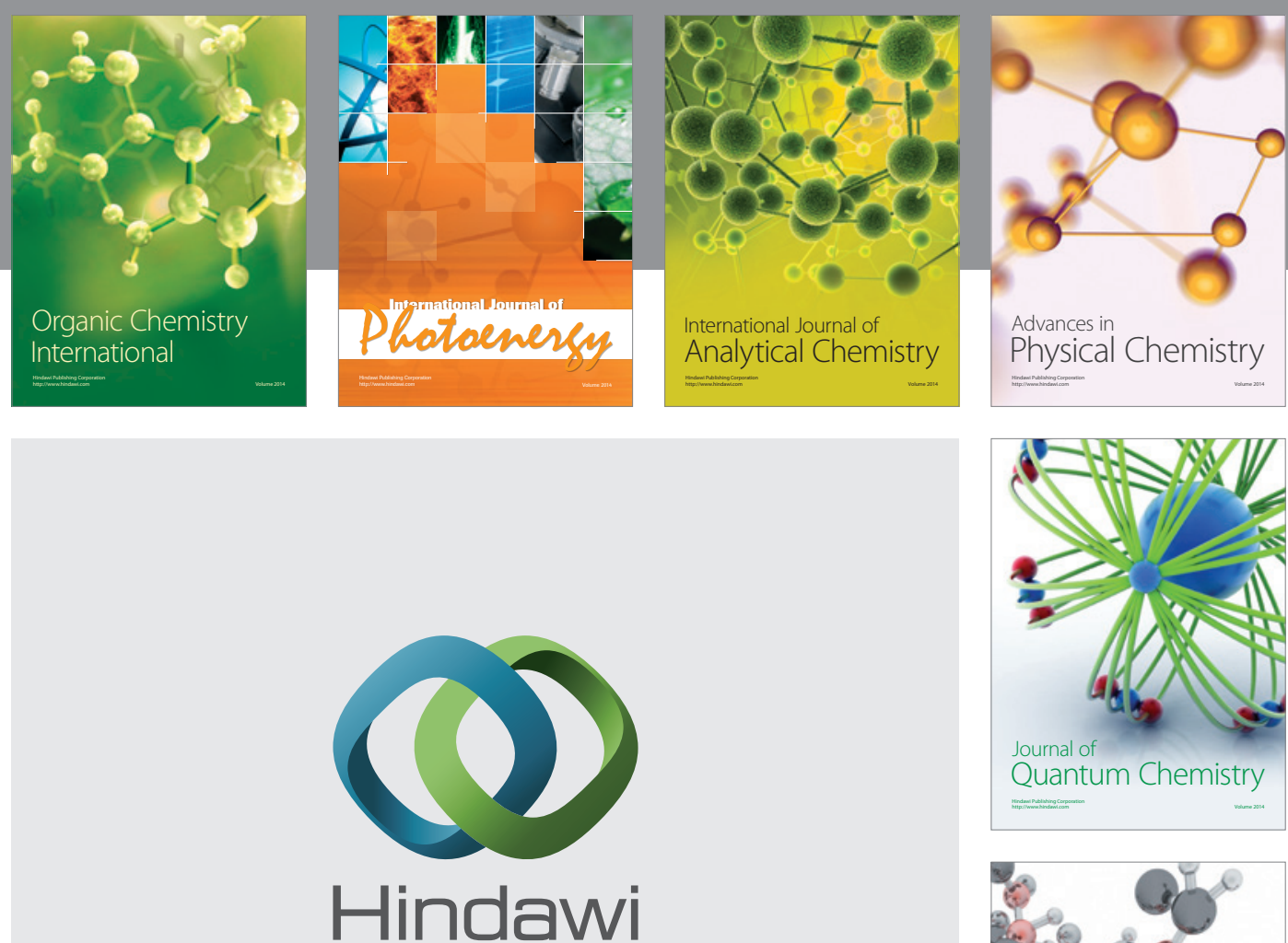

Submit your manuscripts at

http://www.hindawi.com

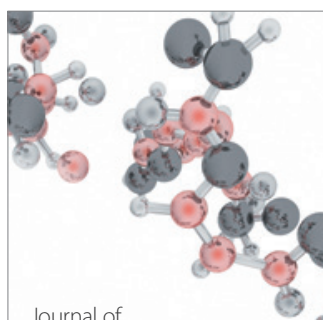

Analytical Methods

in Chemistry

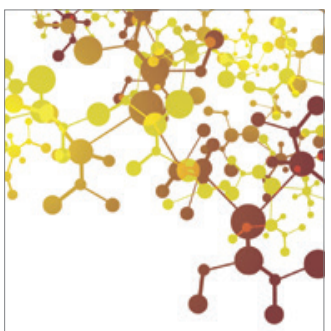

Journal of

Applied Chemistry

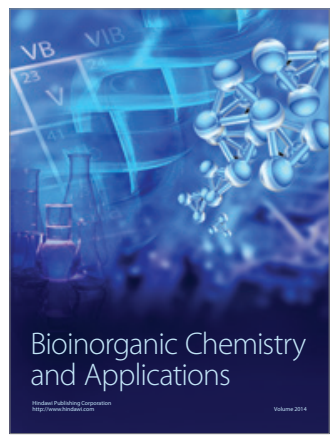

Inorganic Chemistry
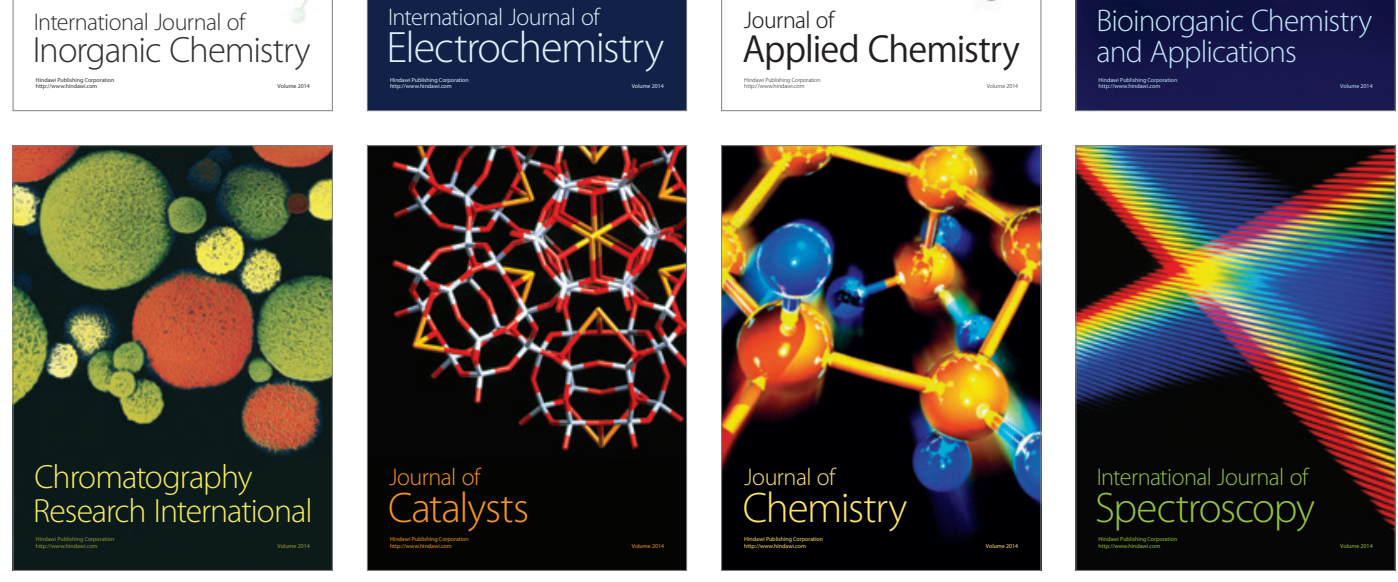